University of Nebraska - Lincoln

DigitalCommons@University of Nebraska - Lincoln

Sociology Department, Faculty Publications

Sociology, Department of

2012

\title{
A cluster analysis of service utilization and incarceration among homeless youth
}

Lisa A. Kort-Butler

University of Nebraska-Lincoln, lkortbutler2@unl.edu

Kimberly A. Tyler

University of Nebraska-Lincoln, kim@ktresearch.net

Follow this and additional works at: https://digitalcommons.unl.edu/sociologyfacpub

Part of the Social Control, Law, Crime, and Deviance Commons

Kort-Butler, Lisa A. and Tyler, Kimberly A., "A cluster analysis of service utilization and incarceration among homeless youth" (2012). Sociology Department, Faculty Publications. 179.

https://digitalcommons.unl.edu/sociologyfacpub/179

This Article is brought to you for free and open access by the Sociology, Department of at DigitalCommons@University of Nebraska - Lincoln. It has been accepted for inclusion in Sociology Department, Faculty Publications by an authorized administrator of DigitalCommons@University of Nebraska - Lincoln. 


\title{
A cluster analysis of service utilization and incarceration among homeless youth
}

\author{
Lisa A. Kort-Butler, Kimberly A. Tyler \\ University of Nebraska-Lincoln, Department of Sociology, United States \\ Corresponding author - L. A. Kort-Butler, University of Nebraska-Lincoln, Department of Sociology, \\ 736 Oldfather Hall, Lincoln, NE 68588-0324, USA; fax 402472 6070, email lkortbutler2@unl.edu
}

\begin{abstract}
Our paper examines service usage (e.g., shelter) as well as a typology of individuals who are most likely to use groupings of services among 249 homeless youth. Our results revealed that the majority of homeless young people have used food programs (66\%) and street outreach $(65 \%)$ on at least one occasion within the past year. Cluster analysis of services revealed four distinct groups: (1) basic survival service use, characterized by above average shelter, food, and outreach service use, but below average on counseling, substance abuse/mental health services, and incarceration; (2) multiple service use, which included above average use of all six services; (3) incarceration experience, characterized by above average incarceration experience, but below average use of all other five services; and (4) minimal service use, which included slightly above average use of counseling, but below average use of all other services. These findings have the potential to provide important information that may assist with targeting services to homeless youth.
\end{abstract}

Keywords: service utilization, incarceration, family histories, street experiences, homeless youth

\section{Introduction}

It is estimated that as many as 1.6 million youth run away from home each year and the majority are between 15 and 17 years of age (Hammer et al., 2002). Many of these young people run from abusive and neglectful families (Tyler and Cauce, 2002), while others leave home due to family conflict (Skott-Myhre et al., 2008) or because of their own behavioral problems (Whitbeck and Hoyt, 1999). Additionally, there is a sizeable group of youth who run away or are forced to leave home because of their sexual orientation (Cochran et al., 2002).

Once youth are on the street, daily survival is difficult. Although some homeless youth take advantage of services such as shelter, drop-in centers, and street outreach (Carlson et al., 2006), other youth face potential barriers including racism, becoming state wards, and inability to afford services (Geber, 1997; Solorio et al., 2006; Wright, 1991). According to researchers, there is another group of youth who choose not to utilize services, because they want to prove that they can succeed on their own (Pergamit and Ernst, 2010) or feel that such programs are constrictive and thus threaten their freedom (Auerswald and Eyre, 2002). Those who are unwilling or unable to access services may resort to illegal activities such as selling drugs or trading sex in order to obtain food, shelter, or other basic necessities (Allen et al., 1994; Kipke et al., 1998; Rotheram-Borus et al., 1992; Tyler et al., 2000). Additionally, many homeless youth become embedded in criminal peer groups, and this association has been found to lead to an increase in crime (Hagan and McCarthy, 1997) and an increase in the number of arrests (Chapple et al., 2004). As such, some homeless youth may wind up in juvenile detention or jail given their affiliation with deviant peers and their participation in illegal activities. Finally, some research suggests that $80 \%$ of street and shelter youth are not receiving effective treatment based on current intervention strategies. As such, there is a persistent need for multifaceted services encompassing behavioral intervention, chemical dependency, and mental health counseling (Coward Bucher, 2008). 
Although services are important for youths' physical and mental well-being and for potentially removing them from the streets permanently, little is known about patterns of service utilization (or non-utilization) among homeless individuals (Kryda and Compton, 2009; Slesnick et al., 2008). As such, the purpose of our paper is twofold: (1) to examine the frequency of service utilization, including shelters, food programs, counseling, and street outreach, as well as mental health/substance use in-patient episodes and incarceration episodes among homeless youth, and (2) use cluster analysis to first identify the patterns of usage and then to describe the characteristics of youth found in those clusters. These findings have the potential to provide important information that may assist with targeting homeless youth based on their clustering of service usage or non-usage.

\section{Literature review}

\subsection{Service utilization}

Research in this area tends to examine a variety of services such as shelter, street outreach, health care, and mental health services. For example, among their sample of 185 homeless youth, Carlson et al. (2006) found that $99 \%$ of respondents had accessed at least one of the following services within the past three months: shelters, outreach, medical, and/or drug-related. The rates of usage were found to vary: $50 \%$ of youth accessed medical services while only $7 \%$ reported using shelters. De Rosa et al. (1999) reported that the most frequently utilized service among their sample of homeless youth was drop-in centers used by $78 \%$ of respondents followed by shelters $(40 \%)$ and medical care $(28 \%)$. Finally, only $10 \%$ of homeless youth utilized substance abuse treatment in their study. Pergamit and Ernst (2010) also found that drop-in centers were utilized most frequently (58\%) within their sample of homeless youth, followed by food programs (54\%), street outreach (41\%), counseling (40\%), and shelter services (33\%). The majority of study youth reported learning about general services via their friends (Pergamit and Ernst, 2010).

\subsection{Variations in service use}

Even though a variety of services may be available to homeless individuals (Carlson et al., 2006), numerous barriers to accessing services exist for homeless youth. These include not knowing what services are available, feeling too embarrassed to talk about concerns, previous negative experience with a staff member, lack of transportation, concerned the agency would contact a social worker or police and thus they would become wards of the state, inability to afford services or lack of health insurance, and not being able to consent for care (Ensign and Bell, 2004; Geber, 1997; Solorio et al., 2006; Wright, 1991). In addition to these barriers, some research finds that three central reasons exist for the lack of service utilization among homeless youth: feeling like they did not need it; not knowing where to find it; and not knowing that a particular service exists (Pergamit and Ernst, 2010).

Homeless youth who do not access services because they feel they do not need them may have other options available. For example, instead of utilizing shelter services, some youth may have the option of staying with a housed friend. Others may have access to shelter for the night but this may come at a great cost. Tyler and Johnson (2006) found that while some women thought they were receiving genuine offers of shelter and free meals, they later found out that the housed male expected sex in return. Other youth may resort to delinquent activities such as conning, stealing, or selling drugs in order to buy food and other items deemed necessary for survival (Whitbeck and Hoyt, 1999). In addition, some youth sell drugs and/or trade sex in order to support their addiction or that of their partner (Tyler and Johnson, 2006). Youth in these situations may avoid shelter and other programs, because they know they would not be able to stay at the shelter while intoxicated and may be referred for treatment. As such, non-service usage youth may be more likely to spend their time on the street, which not only increases their risk for victimization (Tyler et al., 2004) but also increases their chances of associating with deviant peers, which has been found to strongly influence the likelihood of being harassed or arrested by the police (Chapple et al., 2004; Thrane et al., 2008).

In their sample of homeless adolescents, Chapple et al. (2004) found that $52 \%$ had been arrested. Similarly, Thrane et al. (2008) noted that $55 \%$ of their sample had been arrested and $45 \%$ reported being hassled by the police. Whitbeck and Hoyt (1999) found that $42 \%$ of females and $34 \%$ of males had been arrested or spent some time in juvenile detention. Research suggests that runaway youth with arrest histories prior to being on the street may have different, more illicit survival strategies compared to street youth without prior histories of arrest (Chapple et al., 2004). Consequently, it is also likely that some homeless youth do not access legitimate services because they see other (illicit) options, or because they are in juvenile detention or jail. In this sense, incarceration episodes may be meeting a need for shelter, food, and other services usually provided by street outreach organizations or other systems of care (Fischer, 1992). As such, homeless youth who have a history of juvenile detention and incarceration may look very different in terms of their personal histories and service usage compared to those who have not been incarcerated.

Although service utilization is important for homeless youths' survival, many of these young people also rely on their social networks for emotional and material support (Johnson et al., 2005; Smith, 2008). Network members are often instru- 
mental in homeless individuals' survival strategies as they may provide money and/or information on where to obtain food, clothing, or shelter as well as protection from victimization on the street (Auerswald and Eyre, 2002; Smith, 2008). Having a family member in a homeless youths' social network has also been found to protect against risky sexual and/or drug use behaviors (Ennett et al., 1999a; Tyler, 2008). Thus, youth with more robust social supports may be less likely to access other services.

\subsection{Characteristics associated with usage}

Although there is a paucity of research in this area, the studies that do exist on correlates of service utilization tend to focus on youth characteristics. In terms of sex, some research has found that females are more likely to access medical care/ services compared to males (De Rosa et al., 1999; Klein et al., 2000). Woods et al. (2002) report sex and race differences and find that a greater proportion of minority women are being seen at health centers and hospitals compared to their counterparts. Other studies that have looked at race have found that African Americans and Latino homeless youth are more likely to use shelters compared to White youth (De Rosa et al., 1999). In addition to examining youth demographics as correlates of service usage, more research is needed that investigates other domains of the youth's life including their family histories, their amount of time on the street, as well as their street experiences.

\subsection{Justification for cluster analysis}

Prior research using cluster analytic techniques for homeless data has focused largely on identifying typologies of homelessness and the characteristics of people in those typologies, then providing recommendations for the services from which these people might benefit (Adlaf and Zdanowicz, 1999; Coward Bucher, 2008; Kuhn and Culhane, 1998; Milburn et al., 2009). Furthermore, a limitation of prior research on service utilization among homeless youth is that it examines individual service usage rather than patterns of usage. As such, this literature does not reflect the reality of many homeless young people who access several kinds of services or the reality of those who access none at all. The cluster analysis allows us to first identify the patterns of usage and then use Chi-square tests and general linear model procedures (ANOVA) to describe the characteristics of youth found in those clusters. A better understanding of patterns of service among homeless youth use may help service providers tailor their outreach programs.

\section{Data and methods}

\subsection{Study sample}

Data are from the Social Network and Homeless Youth Project, a study designed to examine the effect of social network characteristics on homeless youths' HIV risk behaviors. A total of 249 homeless youth (137 females; 112 males) were interviewed in shelters and on the streets from January 2008 to March 2009 in three Midwestern cities in the United States. The Institutional Review Board (IRB) at the University of Nebraska-Lincoln approved this study. The sample for this study includes youth ages 14-21 who are considered homeless or a runaway on the night prior to the screening. Homeless refers to youth who have spent the previous night with a stranger, in a shelter or public place, on the street, in a hotel room, staying with friends (e.g., couch surfing), or other places not intended as their resident domicile. The term runaway refers to youth under age 18 who have spent the previous night away from home without the permission of parents or guardians (cf. Ennett et al., 1999a).

\subsection{Data collection}

Experienced interviewers who have worked on past homeless youth projects, who have served for several years in agencies and shelters that support at-risk youth, and who were very familiar with local street cultures, such as knowing where to locate youth and where they congregate, conducted the interviews. All interviewers had completed the Collaborative IRB Training Initiative course for the protection of human subjects. Interviewers approached shelter residents and located other eligible respondents in areas of the cities where homeless youth congregate. They varied the times of the day on both weekdays and weekends that they went to these locations. This sampling protocol was conducted repeatedly over the course of 15 months. All participants were administered informed consent. While some respondents were not age of majority, they were mature minors and a request for waiver of parental consent was approved by the supervising IRB. All respondents were told that their responses would remain confidential and that their participation was voluntary. The interviews were typically conducted in shelter conference rooms or quiet corners of fast food restaurants if taking the youth back to the shelter was not feasible because of distance or safety concerns. The interview lasted approximately 45 min and all participants received $\$ 25$ for their involvement and $\$ 5$ for a meal. Referrals for shelter, counseling services, and food services were also offered to youth at the time of the interview. All youth present were screened for eligibility and invited to participate. The response rate was $97 \%$ based on the number of initial contacts. Our response rate is consistent with previous research on homeless and runaway youth which also finds exceptionally high rates (e.g., 95\% and 93\%, Cauce et al., 1998 and Whitbeck et al., 1999, respectively). 


\subsection{Measures}

\subsubsection{Service variables}

Five service utilization variables including shelter, food programs, counseling, street outreach (e.g., agency staff handing out sandwiches, fruit, drinks, blankets), and substance abuse treatment/mental health in-patient episodes were used for the current study as were incarceration episodes. For the first four services listed above, respondents were asked how often they used each of them within the last year. Response categories included: $0=$ never, $1=\mathrm{a}$ few times per year, $2=$ once per month, 3 = a few times per month, $4=1-2$ times per week, and 5 = every day.

De Rosa et al. (1999) listed substance use treatment among their service use variables, so we include a measure of hospitalizations. For substance abuse treatment/mental health in-patient episodes, youth were asked if they ever stayed in a facility for substance abuse and if they ever stayed in a facility for mental health reasons. If they responded affirmatively, they were asked to indicate how many different times they had stayed at each facility. Those who had not used either facility were coded as 0 to retain cases. To create one measure, the two variables were summed, and the new measure was recoded so that $0=$ never stayed in a substance abuse or mental health facility, $1=$ once, $2=$ twice, $3=3-4$ times, $4=5-9$ times, and $5=10$ or more times.

Incarceration episodes were measured based on items that asked youth if they ever spent time in a juvenile detention facility and if they ever spent time in jail. If they responded affirmatively, they were asked to indicate how many different times they had stayed at each facility. Those who had not used either facility were coded as 0 to retain cases. To create one measure, the two variables were summed, and the new measure was recoded so that $0=$ never incarcerated, $1=$ once, 2 = twice, $3=3-4$ times, $4=5-9$ times, and $5=10$ or more times. Fischer (1992) also noted the role incarceration may play in meeting service "needs" among the homeless.

\subsubsection{Youth demographic variables}

Sex was coded $0=$ male and 1 = female. Youth were asked, "How would you describe your sexual orientation?" Sexual orientation was coded $0=$ gay, lesbian, bisexual, transgendered (GLBT) and 1 = heterosexual. Employed recently was a single item indicator that asked respondents, "In the past six months, have you had a job?" $(0=$ No; 1 = Yes). Race was measured by asking respondents "What race or ethnic origin do you consider yourself to be?" White (not of Hispanic origin), Black or African American, Hispanic or Latino, American Indian or Alaskan Native, Asian, biracial, or multiracial. Given that we did not find significant differences between racial/ethnic groups, this variable was dichotomized into $1=$ White and $0=$ Non-White for subsequent analyses. Respondents' age at the time of the interview ranged from 14 to 21 . Youth education was measured by asking respondents "What is the last grade you completed in school? Response categories ranged from $1=$ less than 6 th grade to $12=$ have college degree.

\subsubsection{Family history variables}

Public assistance and public housing were measured by asking respondents if their caretaker ever received public assistance, such as welfare, Aid to Families with Dependent Children, or food stamps and if their caretaker ever lived in public housing or a housing project when they last lived with them $(0=$ No; $1=$ Yes $)$. Group home and foster care were measured by asking respondents "Have you ever lived in a group home?" and "Have you ever lived in foster care?" $(0=$ No; $1=$ Yes). A single item indicator measured whether youth had been kicked out by a parent/caretaker $(0=\mathrm{No} ; 1=\mathrm{Yes})$. Child abuse included two questions: "Were you ever physically abused as a child (under age 18)?" and "Were you ever sexually abused as a child (under age 18)?" (0 = No; 1 = Yes).

\subsubsection{Youth history variables}

Age at first run was an open-ended question that asked youth "How old were you when you first ran away or left home?" Totalnumber of times run was a single item measure which asked youth how many times they had run from home. Response categories were collapsed due to skewness into $1=1$ time, $2=2$ times, $3=3$ times, $4=4-5$ times, $5=6-10$ times, $6=11-20$ times, and $7=21$ or more times. Longest time away from home was an open-ended question which asked respondents, "What was the longest time period that you spent away from home?" Response categories were collapsed due to skewness into $1=1$ month or less, $2=2-4$ months, $3=5-9$ months, $4=10-19$ months, and $5=20$ or more months. Length of most recent run was also an open-ended question that asked youth, "How long have you been away from home this past time?" Response categories were collapsed due to skewness into $1=1$ month or less, $2=2-3$ months, $3=4-6$ months, $4=7-12$ months, $5=13-35$ months, and $6=36$ months or more. All of these measures have been show to be important correlates of various outcomes among homeless youth and are conceptualized similarly to what we have here (cf. Berdahl et al., 2005; Chapple et al., 2004; Chen et al., 2007).

\subsubsection{Street experience variables}

Traded sex was measured by asking participants if they have ever traded sex for food, shelter, money or drugs $(0=$ No; 1 = Yes). Additionally, an open ended question asked youth what kinds of things they had done to get by on the streets when they had few other options. Those who indicated that they had traded sex were also included in this count. Nights 
on the street per week was measured by asking "On average, how many nights a week do you spend on the street?" To obtain an acceptable level of skewness, open ended responses were collapsed into $0=0$ nights, $1=1$ night, $2=2$ nights, $3=3$ nights, $4=4$ or more nights. Sexual victimization was measured by asking respondents four items regarding sexual victimization experiences since leaving home such as whether they had been forced to do something sexual or been sexually assaulted and/or raped. Response categories ranged from $0=$ Never to $3=$ Many times ( 5 or more). The four items were summed such that a higher score indicated more sexual victimization $(a=.85)$. Melander and Tyler (2010) found a similar reliability $(a=.84)$ among a sample of homeless young adults using the same items. Respondents were also asked about five physical victimization experiences since leaving home. These items included the frequency with which they were beaten up, robbed, or threatened with a weapon for example. Responses ranged from $0=$ Never to $3=$ Many times $(5$ or more). The items were combined into a mean scale $(a=.76)$. This scale has been shown to have very good reliability with homeless populations $(a=.82$; Whitbeck and Simons, 1990). Peers' deviant activities was measured using nine items where respondents were asked, for example, whether they had close friends who had stolen, robbed someone, conned someone, or threatened someone with a weapon $(0=$ No; $1=$ Yes $)$. We created an index where a higher value indicated having more close friends who engage in delinquent behavior. This scale also has been shown to have excellent reliability among homeless youth $(a=.89$; Chapple et al., 2004). Sold drugs was a single item which asked youth how often they have sold drugs since they have been on the street $(0=$ Never to $3=$ Many times $[5$ or more). Deviant subsistence strategies was a summed scale of 11 items in which respondents were asked how often they had engaged in a series of behaviors such as stealing, passing bad checks, or beating someone up so badly they needed to see a doctor since they left home. Response categories ranged from $0=$ Never to $3=$ Many times ( 5 or more). Cronbach's alpha was 0.88 . This scale has been shown to have good reliability among homeless populations $(a=.73$, Tyler et al., 2001; and $a=.75$, Whitbeck and Simons, 1990).

Sexual risk index was a count of four individual dichotomized items where a higher score indicates more sexual risk taking: youth ever had voluntary sexual intercourse $(0=\mathrm{No} ; 1=$ Yes $)$; age at first sex dichotomized at median $(0=$ ages 16-20; 1 = ages 8-15); number of sexual partners in the past 12 months dichotomized at median $(0=0-2 ; 1=3$ or more); and, number of lifetime sexual partners dichotomized at median $(0=0-7 ; 1=8$ or more). Exploratory factor analyses supported the inclusion of all four risk factors in one index. All items had loadings of more than 0.6 and these items were significantly correlated. The use of dichotomizing individual items to create an index of high risk sexual behaviors has been used in both general population studies (cf. Scott et al., 2011) and studies on homeless youth (cf. Ennett et al., 1999b).

\subsubsection{Social network variables}

Network support included five items regarding who youth would turn to if they needed help with instrumental (e.g., borrow money), protective (being hassled), personal (e.g., private matter), advice (e.g., health problem), and emotional support. Youth were asked to list the initials of people in their network who provided support in all of these five categories. These five individual items were summed across network members to create a general scale of social support. The scale could potentially range from 0 (no one to rely on) to 40 (eight people they could rely on in each of the five categories). The actual range was 0-25. Family member in network was measured by asking youth their relationship to each person in their social network. Because we were only interested in whether a family member was present, we dichotomized this item into $0=$ non family member and 1 = at least one family member present.

\subsection{Data analyses}

After examining the frequencies for service utilization and incarceration episodes, we then assessed patterns of service utilization and incarceration with cluster analysis (Aldenderfer and Blashfield, 1984). After standardizing the frequency of service use variables, the substance use/mental health in-patient episodes variable, and the incarceration episodes variable, the cluster analysis proceeded in two stages. First, the six variables were submitted to a hierarchical cluster analysis using a squared Euclidian distance measure with Ward's method, which applies an algorithm to identify homogenous groups of variables. The hierarchical analysis indicated four clusters within the data. Second, to confirm this clustering, the data were submitted to a K-means cluster analysis (cf. Coward Bucher, 2008). K-means analysis also attempts to identify homogenous groups but requires the user to indicate a pre-determined number of clusters. In the first pass through the data, the procedure assigns the data randomly to the specified number of clusters and calculates a centroid. The procedure then goes through several iterations of assigning and reassigning cases to clusters until no further changes are required to minimize differences within groups but maximize differences between groups. At the end of the iteration sequence, each case is assigned to a cluster. Because the hierarchical analysis indicated four potential clusters, we alternately tested three, four, and five cluster solutions. The four cluster solution appeared to best fit the data.

To determine how clusters varied by youth characteristics, personal histories, family histories, street experiences, and social network support, cross-tabulations were performed with each categorical variable by cluster. Chi-square tests were used to determine whether there was a general difference across clusters. To determine where significant differences existed between clusters, pairwise comparisons of column proportions were conducted using z-tests. For the continuous variables, general linear models (ANOVAs) were performed and comparisons between cluster means were conducted using $t$-tests. To adjust for multiple comparisons, $p$-values were adjusted with the Bonferroni correction. 


\section{Results}

\subsection{Sample characteristics}

Our sample included 137 females (55\%) and 112 males (45\%). Ages ranged from 14 to 21 with a mean of 18.5 years. Of the 249 respondents, $44 \%$ or $17.7 \%$ self-identified as GLBT. Approximately half the sample was White (49.4\%) with the remaining respondents self-identifying as Black (23.7\%), Hispanic (8\%), American Indian or Alaskan native (4.8\%), Asian $(1.2 \%)$, biracial $(8.8 \%)$, and multiracial $(4 \%)$. Nearly $40 \%$ of the sample had completed 12 th grade or earned a GED, and $6.8 \%$ had attended at least some college. A majority of youth (55\%) had been physically abused at least once and onethird $(33 \%)$ reported that they had been a victim of sexual abuse. Forty-six percent of youth reported having been kicked out of their home. Youth reported running an average of 3 times; however, almost 15\% of the sample had run 11 times or more. Twelve percent of the sample spent an average of 1-2 nights per week on the street, but almost $11 \%$ reported spending an average of 4 or more nights per week on the street. A total of $48 \%$ of youth have ever lived in a group home and $37 \%$ have spent time in foster care.

\subsection{Service utilization and incarceration frequencies}

Table 1 shows the frequency of service usage among youth within the past year. Given their different response categories, the frequency results for in-patient and incarceration episodes are not shown in the table but are reported below. Almost $27 \%$ of youth said they were using a shelter daily, and 17\% were using some type of food program on a daily basis. In contrast, we also see youth on the other end of the continuum with $44 \%$ reporting never using shelter, $34 \%$ never using food programs, $57 \%$ never using counseling services, or 35\% never using street outreach. Additionally, about half the sample had no in-patient episodes, but $37 \%$ had been hospitalized one to four times. Only $33 \%$ of the sample had never been incarcerated, but nearly $58 \%$ had been incarcerated one to four times.

\subsection{Cluster analysis}

The cluster analysis indicated 4 clusters, or patterns, of service utilization (see Figure 1). Cluster 1, basic survival service use $(n=82)$, was characterized by above average shelter, food, and outreach service use, but below average on counseling, substance abuse/mental health in-patient episodes, and incarceration episodes. Cluster 2, multiple service use ( $n=42)$, was characterized by above average use of all five services and incarceration episodes. Cluster 3 , incarceration experience $(n=47)$, was characterized by above average incarceration episodes, but below average use of all other five services. Cluster 4, minimal service use $(n=77)$, was characterized by slightly above average use of counseling, but below average use of all other services and incarceration.

Table 2 presents average service use within each cluster. Confirming the cluster analysis, tests indicated that service usage, in-patient episodes, and incarceration episodes differed significantly across clusters. For example, youth in the incarceration experience cluster had significantly less service use across all categories but significantly more incarceration episodes.

After establishing the clusters, we then used chi-square and general linear modeling (ANOVA) procedures to determine how youth characteristics, personal histories, family histories, street experiences, and social network variables differed across clusters. The top half of Table 3 presents cross-tabulation comparisons and the bottom half of this Table presents the results from ANOVAs for the 4 clusters. In terms of youth demographics, the four clusters were significantly different on recent employment, age, and education. Nearly three-quarters of the youth in the basic survival service cluster had been recently employed, compared to fewer than half the youth in the minimal service cluster. Youth in the minimal service cluster were also significantly younger and less educated than youth in other clusters. There were also significant differences in family history across clusters. More than three-quarters of the youth in the multiple service cluster had lived in a group home, compared to fewer than half the youth in the basic survival service and minimal service clusters. More than half the youth in the multiple service cluster had lived in a foster home, compared to only about one-quarter of the youth in the minimal service cluster. The multiple service cluster also had the largest proportion of youth who had experienced physical and sexual abuse, while the minimal service cluster had the smallest proportion. About two-thirds of the youth in the incarceration cluster had been kicked out, compared to about one-third of youth in the minimal service cluster.

Table 1. Frequency of service utilization in the past year.

\begin{tabular}{|c|c|c|c|c|c|c|c|c|c|c|c|c|}
\hline & \multicolumn{2}{|c|}{ Never } & \multicolumn{2}{|c|}{$\begin{array}{l}\text { Few times } \\
\text { per year }\end{array}$} & \multicolumn{2}{|c|}{$\begin{array}{l}\text { Once } \\
\text { per month }\end{array}$} & \multicolumn{2}{|c|}{$\begin{array}{l}\text { Few times } \\
\text { per month }\end{array}$} & \multicolumn{2}{|c|}{$\begin{array}{l}\text { 1-2 times } \\
\text { per week }\end{array}$} & \multicolumn{2}{|c|}{ Everyday } \\
\hline & $\mathrm{N}$ & $\%$ & $\mathrm{~N}$ & $\%$ & $\mathrm{~N}$ & $\%$ & $\mathrm{~N}$ & $\%$ & $\mathrm{~N}$ & $\%$ & $\mathrm{~N}$ & $\%$ \\
\hline How often do you participate in food programs? & 84 & 33.7 & 28 & 11.2 & 10 & 4.0 & 41 & 16.5 & 43 & 17.3 & 43 & 17.3 \\
\hline How often do you use counseling services? & 143 & 57.4 & 27 & 10.8 & 10 & 4.0 & 29 & 11.6 & 35 & 14.1 & 5 & 2.0 \\
\hline How often do you use street outreach services? & 88 & 35.3 & 38 & 15.3 & 18 & 7.2 & 32 & 12.9 & 43 & 17.3 & 30 & 12.0 \\
\hline
\end{tabular}




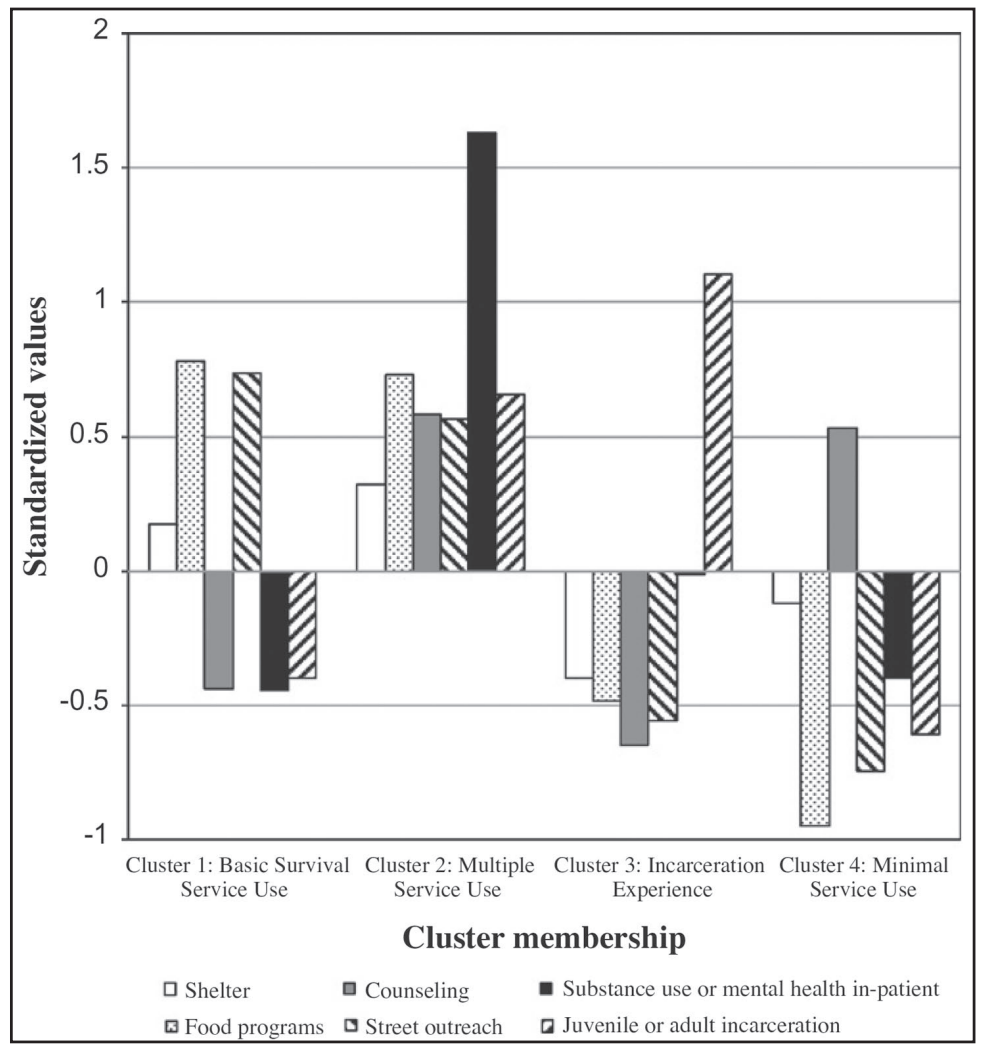

Figure 1. Service use cluster patterns.

Table 2. Average service use within clusters.

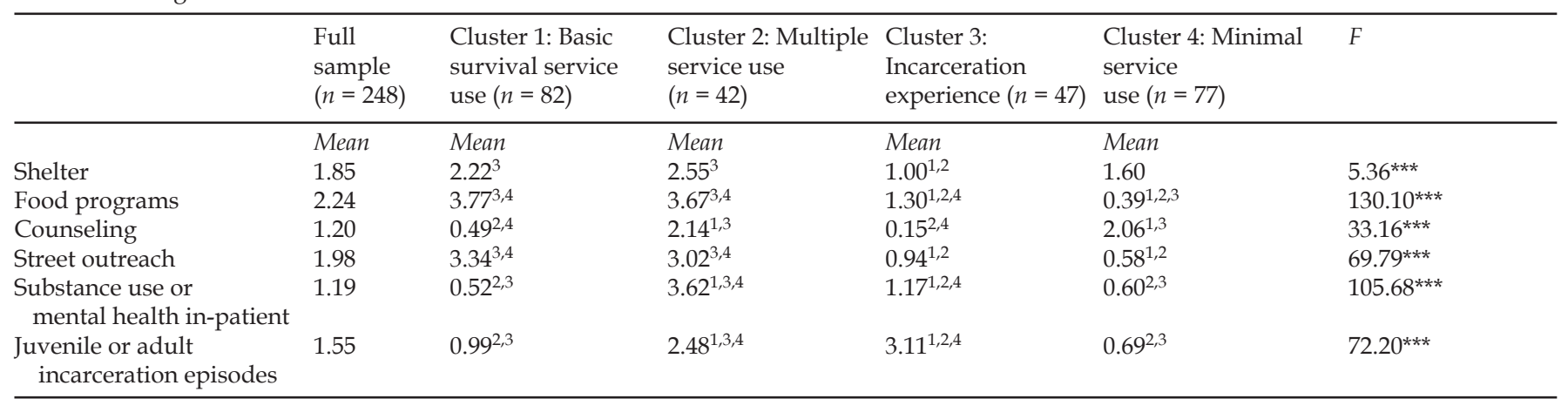

ANOVA tests across clusters. Superscript indicates clusters that are significantly different at $p<.0 .5$. Shelter, food program, counseling, and street outreach were average use in the past year. In-patient and incarceration episodes were lifetime counts. $* * * p<.001$

There were also significant differences across clusters in running away behavior (see bottom half of Table 3). Youth in the multiple service cluster had first run away from home at the youngest age, slightly older than 12 years of age on average, compared to youth in the basic survival service and minimal service clusters, who were on average two years older when they first ran from home. Youth in the multiple service cluster also ran away more frequently, about two times more often on average than youth in the basic survival and minimal service clusters. During their most recent episode of running away, youth in the multiple service cluster had been away from home the longest, while youth in the minimal service cluster had been away the least amount of time.

The four clusters significantly varied in their street experiences, particularly between the multiple service and minimal service clusters. Youth in the multiple service cluster had the highest mean levels of nights per week spent sleeping on the street, sexual victimization, physical victimization, deviant peers, trading sex, selling drugs, deviance subsistence strategies, and sexual risk behavior. In contrast, youth in the minimal service cluster had the lowest mean levels of these street 
Table 3. Chi-square and ANOVA tests of cluster differences.

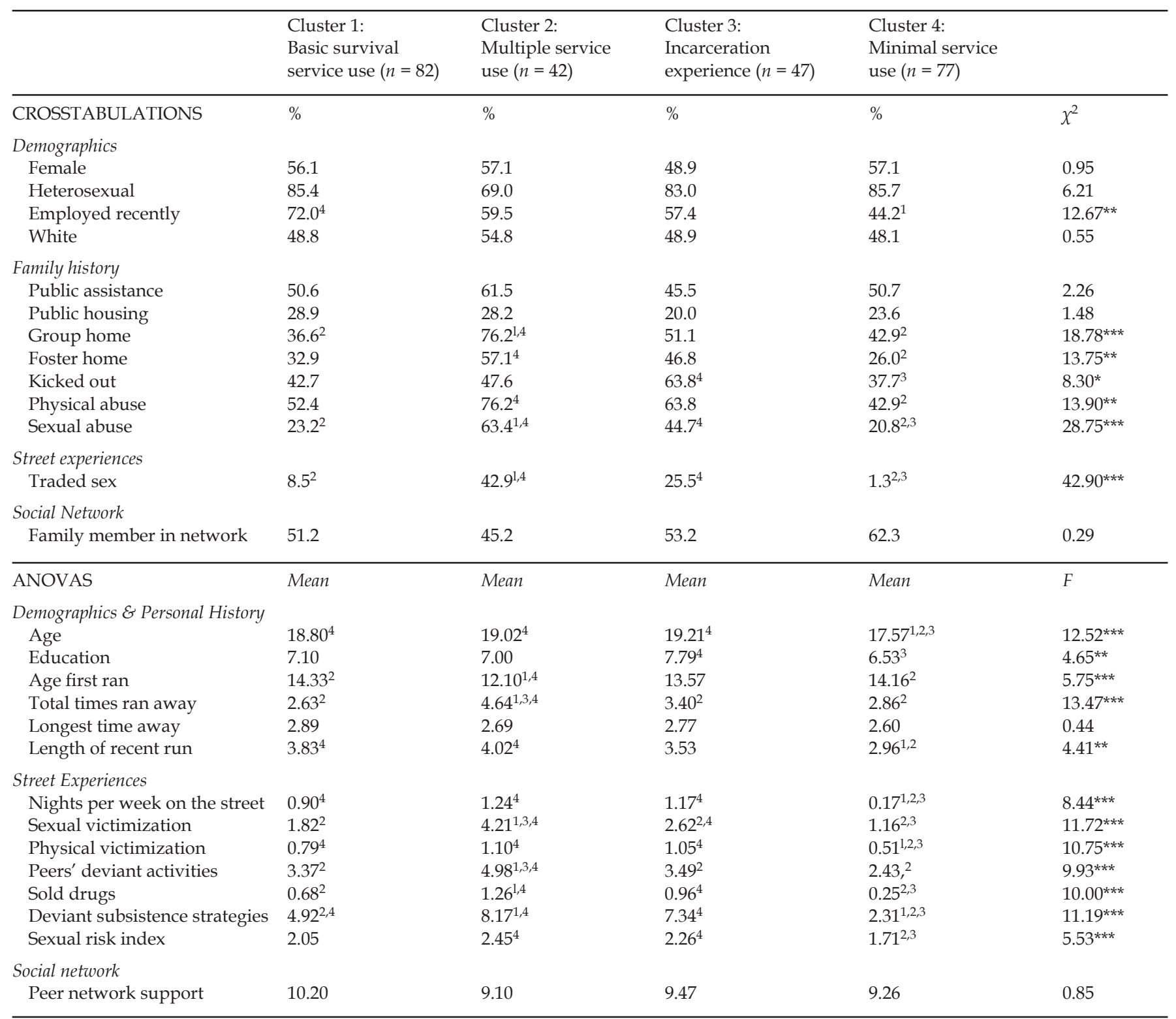

Superscript indicates clusters that are significantly different at $p<.05$.

${ }^{*} p<.05 ;{ }^{* *} p<.01 ;{ }^{* *} p<.001$

experiences. Several contrasts emerged between the incarceration and minimal service clusters, as youth in the incarceration cluster had the second highest mean levels of these experiences. There was no difference across the clusters on the two social network measures.

\section{Discussion}

The purpose of our paper was to (1) examine the frequency of service utilization including shelters, food programs, counseling, street outreach, mental health and substance use in-patient episodes, and incarceration episodes among homeless youth, and (2) use cluster analysis to identify the patterns of usage and then to describe the characteristics of youth found in those clusters. Currently, little is known about general service usage patterns among homeless youth even though this is a vulnerable population that often faces barriers to using services but is a group in need of such resources. Failure to reach out to these high-risk youth may result in continued participation in risky behaviors, which may have long-term negative effects. 
Our findings indicated that numerous youth take advantage of a variety of services while on the street. More than half of our sample had utilized street outreach services (65\%) or food programs (66\%) in the past year. Additionally, $56 \%$ reported staying at a shelter and another $43 \%$ of youth indicated they had used counseling services within the past 12 months. There was also a sizeable group, however, who had not accessed such services: $44 \%$ of respondents had not used a shelter, $57 \%$ had not had counseling, and $35 \%$ had not taken advantage of street outreach. It is possible that youth who were not accessing these services were unaware that they existed, did not feel they needed them, or perhaps did not want to use them for a variety of reasons such as not wanting to follow center rules, concerns about confidentiality, or simply not trusting the staff (Geber, 1997; Solorio et al., 2006). Results from cluster analysis revealed a group of homeless youth who used multiple services, and had a history of staying in a substance use/mental health in-patient facility and being incarcerated. These youth may be more likely to use a broader range of services for several reasons. First, because they ran at an earlier age, ran away more frequently, and had been away from home the longest with their most recent run compared to youth in other clusters, they may be more familiar with services and how to access them. Second, more of these youth had a history of physical and sexual abuse, and experienced more physical and sexual victimization on the street. As a result, these youth may be in greater need for services. Third, we found that youth in the multiple service use cluster were more involved in risky activities, including deviant subsistence strategies, risky sexual behavior, associating with deviant peers, as well as spending more nights per week on the street. Again, such risky behaviors may put these youth in greater need of services. Relatedly, because many homeless youth report learning about general services from their friends (Pergamit and Ernst, 2010), associating with a larger number of deviant peers may also account for the greater usage of resources among this group. It should be noted, however, that even though youth in the multiple service cluster accessed the broadest range of services, they were by no means receiving all the services they may have required, as indicated by the fact that they were only using these particular services once to a few times per month.

In contrast to the youth in the multiple service use cluster, youth in the minimal service cluster, characterized by the use of counseling but very little use of the other services, were younger and had the least education. They also first ran away from home at a later age, ran less frequently, and had the shortest recent run. As a result, they may be less familiar with resource availability and how to access resources. Given their less extensive running history, it is also possible they may not have fully exhausted requests for assistance from other sources (e.g., friends, other relatives) in ways not assessed by the social network measures. Youth in this cluster may also have had less need for services. For example, fewer youth in this cluster had experienced early abuse and street victimization relative to others. These youth were also less involved in risky behaviors. Research on newly homeless adolescents implies that within this group, there may be variation in risk and protective factors (Milburn et al., 2009). Although their current needs may not be immediate, if they continue to spend time on the streets, they may find themselves in greater need of basic survival services such as food and shelter.

In fact, the youth in the basic survival service cluster may be a look into the future of the youth in the minimal service cluster. The youth in these two clusters had relatively similar family histories, their average age at first run was approximately the same, and both groups had run away about the same number of times. The youth in the basic survival service cluster, however, were about a year older on average and had been away from home for a longer time period. They also experienced higher risk; in particular, the youth in the basic survival service cluster spent more nights sleeping on the street, experienced more physical victimization, and engaged in more deviant subsistence strategies compared to youth in the minimal service cluster. These results suggest that the longer youth in the minimal service cluster are away from home, the greater the likelihood that they may be victimized and participate in illicit activities, thus having a greater need for services in the near future.

Youth in the incarceration cluster were characterized by more incarceration episodes. Youth in this cluster were second only to youth in the multiple service cluster in terms of abuse histories, running away profiles, street victimization, and risky behaviors on the streets. The largest contrast was in the number of youth in each cluster who were kicked out of their homes: almost two-thirds of youth in the incarceration cluster had been kicked out by a parent/caretaker, compared to less than half the youth in the other three clusters. Perhaps the behavior of the youth in the incarceration cluster was more likely to draw intervention from the justice system. For reasons we could not measure, a portion of street youth were more likely to have their behavior criminalized instead of being able to access available legitimate street resources. Youth may also have been shut out of legitimate resources as a result of their incarceration histories. Finally, it is possible that some youth were afraid of going to agencies for help if they did not want to be detected (e.g., parole violations), may have heard from their peers that certain agencies do not assist people with a history of incarceration, or may feel excluded (even if agencies do not exclude youth with criminal backgrounds), and thus did not take advantage of services because of this perception.

\subsection{Limitations}

Our findings are limited in terms of generalizability due to the reliance on a convenience sample. Additional limitations include the use of cross-sectional data and self-reported measures. Although the service measures asked about frequency of use in the past year, the in-patient and incarceration variables counted lifetime episodes. As such a portion of our sample could have had experiences prior to becoming homeless (cf. Chapple et al., 2004). However, McAllister et al. (2011) suggest typologies regarding homelessness can include current and past history, that they do not have to be temporally 
constricted, and may yield better results depending on the theoretical or practical purpose for creating such types. Finally, because sexual and physical abuse were not defined for the respondent, it is likely that some youth underreported their experience with child maltreatment.

\subsection{Conclusions}

Overall, our findings reveal that numerous homeless youth take advantage of various services at some point while on the street, but there is also a sizeable group of young people who do not. Additionally, it is noteworthy that even youth who fall under the multiple service cluster were only accessing services approximately once to a few times per month even though they experienced the greatest risks, including child abuse, street victimization, and participation in numerous risky behaviors. On the one hand, the group with the most precarious histories and street experiences were seeking numerous services. On the other hand, they may not be accessing them as much as needed. For example, $43 \%$ of youth in the multiple service cluster had traded sex for food, shelter, money or drugs, and among the clusters they sold drugs and engaged in other deviant subsistence strategies most frequently, suggesting that they may have resorted to dangerous and illegal activities for survival on at least some occasions rather than accessing services. It is possible that at the time of trading sex, for example, they were not aware of particular services or were not able to access them at the time they were needed. Youth in the incarceration cluster had the second highest rate of trading sex, selling drugs, and use of other deviant subsistence strategies. It is possible that youth in both these clusters were engaging in these two behaviors at similar rates at some point, but those in the incarceration cluster were more likely to be apprehended and charged, perhaps because they could not or did not access legitimate services, compared to those in the multiple service use group.

The use of cluster analysis provides insight into the patterning of services that homeless youth utilize as well as youth characteristics, family histories, and street experiences that are associated with each typology. Although longitudinal analysis would be needed to determine if homeless youth progress from one typology to another, our findings suggest that the youngest aged group, characterized by minimal service use, had the shortest time away from home on their most recent run and had run away for shorter time intervals compared to other groups. Because they had not spent as much time on the street, their current need for services may not have been as great as the other groups. However, the more time youth in the minimal service cluster spend on the street, they may find themselves progressing to basic survival service use, before moving to multiple service usage. The percentages for physical and sexual abuse and trading sex, and the rates for street victimization, peers' deviant activities, selling drugs, deviant subsistence strategies, and sexual risk behavior, support this trend.

\subsection{Implications}

Similar to other research on street youth, we found that there was variation among street youth on characteristics associated with risk and potential unmet needs (Adlaf and Zdanowicz, 1999; Coward Bucher, 2008). Overall, our findings revealed that cluster membership was not dependent on race, gender, or sexual orientation, but rather on abuse history, running history, and street experiences. Consequently, avenues for transitioning youth from the streets to more stable living situations may be different for different clusters. Such differences in experiences need to be considered by agency providers when targeting these individuals. Because numerous homeless youth may be cautious of using services or have perceptions that exclude them from taking advantage of these resources, we need to be creative in making services accessible to all homeless youth and letting these young people know services exist. Additionally, we must keep in mind that many homeless youth do not trust most adults because of previous negative experiences (e.g., child abuse). Therefore, agencies will need to create unique situations and strategies that will maximize the likelihood that youth will take advantage of services. Failure to do so may result in their participation in dangerous and illegal activities to meet their basic needs. Additionally, not knowing about services or feeling excluded could potentially lead to incarceration for some homeless young people, or at the very least, mental and physical health problems, and potentially long-term homelessness.

Our results indicate a one-size-fits-all approach to meeting the needs of homeless youth is not efficient. Rather, researchers and practitioners must work to design service and intervention programs to meet the needs of different types or clusters of street youth. Doing so may require inter-agency collaboration. For example, if there are a group of street youth who are "serviced" by the justice system, justice officials could interface with outreach organizations to find more appropriate services, such as housing or substance use treatment. Policy makers concerned with homeless youth should also be aware that just because a youth accesses multiple services, it does not mean his or her needs are being met, either for basic survival or for transitioning off of the streets. Thus, the goal must be to provide youth with the tools and resources necessary to move back into mainstream society. Although this will be a slow process, we believe this can be accomplished with the use of creative strategies, time investment, resources, and the willingness of agencies that support these high risk youth.

Acknowledgment - This research was supported by a Grant from the National Institute on Drug Abuse (DA021079). Dr. Kimberly A. Tyler, PI. 


\section{References}

Adlaf, Edward M., Zdanowicz, Yola M., 1999. A cluster-analytic study of substance problems and mental health among street youths. American Journal of Drug and Alcohol Abuse 25, 639-660.

Aldenderfer, Mark S., Blashfield, Roger K., 1984. Cluster Analysis. Sage Series on Quantitative Applications in the Social Sciences, Series No. 07-044. Sage, Beverly Hills, CA.

Allen, David M., Lehman, Stan, Green, Timothy A., Lindegren, Mary Lou., Onorato, Ida, Forrester, Willisthe, 1994. HIV infection among homeless adults and runaway youth, United States, 1989-1992. AIDS 8, 1593-1598.

Auerswald, Colette L., Eyre, Stephen L., 2002. Youth homelessness in San Francisco: a life cycle approach. Social Science and Medicine 54, 1497-1512.

Berdahl, Terceira A., Hoyt, Dan R., Whitbeck, Les B., 2005. Predictors of first mental health service utilization among homeless and runaway adolescents. Journal of Adolescent Health 37, 145-154.

Carlson, Jennifer L., Sugano, Eiko, Millstein, Susan G., Auerswald, Colette L., 2006. Service utilization and the life cycle of youth homelessness. Journal of Adolescent Health 38, 624-627.

Cauce, Ana Marie, Matthew Paradise, Lara Embry, Charles J. Morgan, Yvette Lohr, James Theofelis, Jennifer Heger, Victoria Wagner, 1998. Homeless youth in seattle: youth characteristics, mental health needs, and intensive case management. In: Krista Kutash, Al Duchnowski, Mike Epstein (Eds.), Community- Based Programming for Children with Serious Emotional Disturbances: Research and Evaluation. Brookes Publishing, Baltimore, MD, pp. 611-632.

Chapple, Constance L., Johnson, Kurt D., Whitbeck, Les B., 2004. Gender and arrest among homeless and runaway youth: an analysis of background, family, and situational factors. Youth Violence and Juvenile Justice 2, 129-147.

Chen, Xiaojin, Thrane, Lisa, Whitbeck, Les B., Johnson, Kurt D., Hoyt, Dan R., 2007. Onset of conduct disorder, use of delinquent subsistence strategies, and street victimization among homeless and runway adolescents in the midwest. Journal of Interpersonal Violence $22,1156-1183$.

Cochran, Bryan N., Stewart, Angela J., Ginzler, Joshua A., Cauce, Ana Mari, 2002. Challenges faced by homeless sexual minorities: comparison of gay, lesbian, bisexual, and transgender homeless adolescents with their heterosexual counterparts. American Journal of Public Health 92, 773-777.

Coward Bucher, Carrie E., 2008. Toward a needs-based typology of homeless youth. Journal of Adolescent Health 42, 549-554.

De Rosa, Christine Johnson, Montgomery, Susanne B., Kipke, Michele D., Iverson, Ellen, Ma, Joanne L., Unger, Jennifer, 1999. Service utilization among homeless and runaway youth in Los Angeles, California: rates and reasons: erratum. Journal of Adolescent Health 24, 449-458.

Ennett, Susan T., Susan, L., Bailey, E., Federman, Belle, 1999a. Social network characteristics associated with risky behaviors among runaway and homeless youth. Journal of Health and Social Behavior 40, 63-78.

Ennett, Susan T., Belle Federman, E., Bailey, Susan L., Ringwalt, Christopher L., Hubbard, Michael L., 1999b. HIV-risk behaviors associated with homelessness characteristics in youth. Journal of Adolescent Health 25, 344-353.

Ensign, Josephine, Bell, Michelle, 2004. Illness experiences of homeless youth. Qualitative Health Research 14, 1239-1254.

Fischer, Pamela J., 1992. The Criminalization of Homelessness. In: Robertson, M.J., Greenblatt, M. (Eds.), Homelessness: A National Perspective. Plenum Press, New York, pp.57-64.

Geber, Gayle M., 1997. Barriers to health care for street youth. Journal of Adolescent Health 21, 287-290.

Hagan, John, McCarthy, Bill, 1997. Mean Streets: Youth Crime and Homelessness. Cambridge University Press, New York.

Hammer, Heather, Finkelhor, David, Sedlak, Andrea J., 2002. Runaway/Thrownaway Children: National Estimates and Characteristics. Online: http://www.ncjrs.gov/html/ojjdp/nismart/04/

Johnson, Kurt D., Whitbeck, Les B., Hoyt, Dan R., 2005. Predictors of social network composition among homeless and runaway adolescents. Journal of Adolescence 28, 231-248.

Kipke, Michele D., Unger, Jennifer B., Palmer, Raymond F., Iverson, Ellen, O'Connor, Susan. 1998. Association between self-identified peer-group affiliation and HIV risk behaviors among street youth. In: Greenberg, J.B., NeumannAtlanta, M.S. (Eds.), What We Have Learned from the AIDS Evaluation of Street Outreach Projects. Center for Disease Control, GA, pp. 61-82.

Klein, Jonathan D., Woods, Amie Hall, Wilson, Karen M., Prospero, Moises, Greene, Jody, Ringwalt, Chris, 2000. Homeless and runaway youths' access to health care. Journal of Adolescent Health 27, 331-339.

Kryda, Aimee D., Compton, Michael T., 2009. Mistrust of outreach workers and lack of confidence in available services among individuals who are chronically street homeless. Community Mental Health Journal 45, 144-150.

Kuhn, Randall, Culhane, Dennis P., 1998. Applying cluster analysis to test a typology of homelessness by pattern of shelter utilization: results from the analysis of administrative data. American Journal of Community Psychology 26, 207-232.

McAllister, William, Lennon, Mary Clare, Kuang, Li, 2011. Rethinking research on forming typologies of homelessness. American Journal of Public Health 101, 596-601.

Melander, Lisa A., Tyler, Kimberly A., 2010. The effect of early maltreatment, victimization, and partner violence on HIV risk behavior among homeless young adults. Journal of Adolescent Health 47, 575-581. 
Milburn, Norweeta, Liang, Li.-Jung, Lee, Sung.-Jae, Rotheram-Borus, Mary Jane, Rosenthal, Doreen, Mallett, Shelley, Lightfoot, Marguerita, Lester, Patricia, 2009. Who is doing well? A typology of newly homeless adolescents. Journal of Community Psychology 37, 135-147.

Pergamit, Michal E., Ernst, Michelle, 2010. Runaway youth's knowledge and access of services. Online: http://www.nrscrisisline.org/ media/documents/NORC_Final_Report_4_22_10.pdf

Rotheram-Borus, Mary, Jane, Heino F., Meyer-Bahlburg, Cheryl, Koopman, Margaret, Rosario, Theresa M., Exner, Ronald, Henderson, Marjory, Matthieu,

Rhoda Gruen, 1992. Lifetime sexual behaviors among runaway males and females. The Journal of Sex Research 29, 15-29.

Scott, Mindy E., Wildsmith, Elizabeth, Welti, Kate, Ryan, Suzanne., Schelar, Erin, Steward-Streng, Nicole R., 2011. Risky adolescent sexual behaviors and reproductive health in young adulthood. Perspectives on Sexual and Reproductive Health 43, 110-118.

Skott-Myhre, Hans A., Raby, Rebecca, Nikolaou, Jamie, 2008. Towards a delivery system of services for rural homeless youth: a literature review and case study. Child Youth Care Forum 37, 87-102.

Slesnick, Natasha, Kang, Min Ju, Bonomi, Amy E., Prestopnik, Jillian L., 2008. Six- and twelve-month outcomes among homeless youth accessing therapy and case management services through an urban drop-in center. Health Services Research 43, $211-229$.

Smith, Hilary, 2008. Searching for kinship: the creation of street families among homeless youth. American Behavioral Scientist 51, 756-771.

Solorio, Rosa M., Milburn, Norweeta, Andersen, Ronald M., Trifskin, Sharone, Rodríguez, Michael A., 2006. Emotional distress and mental health service use among urban homeless adolescents. Journal of Behavioral Health Services and Research 33, $381-393$.

Thrane, Lisa, Chen, Xiaojin, Johnson, Kurt, Whitbeck, Les B., 2008. Predictors of police contact among midwestern homeless and runaway youth. Youth Violence and Juvenile Justice 6, 227-239.

Tyler, Kimberly A., 2008. Social network characteristics and risky sexual and drug related behaviors among homeless young adults. Social Science Research 37, 673-685.

Tyler, Kimberly A., Cauce, Ana Mari, 2002. Perpetrators of early physical and sexual abuse among homeless and runaway adolescents. Child Abuse and Neglect 26, 1261-1274.

Tyler, Kimberly A., Hoyt, Dan R., Whitbeck, Les B., 2000. The effects of early sexual abuse on later sexual victimization among female homeless and runaway youth. Journal of Interpersonal Violence 15, 235-250.

Tyler, Kimberly A., Hoyt, Dan R., Whitbeck, Les B., Cauce, Ana Mari, 2001. The impact of childhood sexual abuse on later sexual victimization among runaway youth. Journal of Research on Adolescence 11, 151-176.

Tyler, Kimberly A., Johnson, Katherine A., 2006. Trading sex: voluntary or coerced? The experiences of homeless youth. Journal of Sex Research 43, 208-216.

Tyler, Kimberly A., Whitbeck, Les B., Hoyt, Dan R., Cauce, Ana Mari, 2004. Risk factors for sexual victimization among male and female homeless and runaway youth. Journal of Interpersonal Violence 19, 503-520.

Whitbeck, Les B., Hoyt, Dan R., 1999. Nowhere to Grow: Homeless and Runaway Adolescents and Their Families. Aldine de Gruyter, New York, NY.

Whitbeck, Les B., Hoyt, Dan R., Yoder, Kevin A., 1999. A risk-amplification model of victimization and depressive symptoms among runaway and homeless adolescents. American Journal of Community Psychology 27, 273-296.

Whitbeck, Les B., Simons, Ronald L., 1990. Life on the streets: the victimization of runaway and homeless adolescents. Youth and Society 22, 108-125.

Woods, Elizabeth R., Samples, Cathryn L., Melchiono, Maurice W., Keenan, Peter M., Fox, Durrell J., Harris, Sion Kim, and the Boston HAPPENS Program Collaborators. 2002. Initiation of Services in the Boston HAPPENS Program: Human Immunodeficiency VirusPositive, Homeless, and At-Risk Youth Can Access Services. AIDS Patient Care and STDs, vol. 16. pp. 497-510.

Wright, James D., 1991. Health and the homeless teenager: evidence from the national health care for the homeless program. Journal of Health \& Social Policy 2, 15-35. 